\title{
A User Experience Evaluation of the use of Augmented and Virtual Reality in Visualising and Interpreting Roman Leicester 210AD (Ratae Corieltavorum)
}

\author{
By Nick Higgett \\ Yanan Chen ${ }^{+}$ \\ Eric Tatham
}

An earlier paper presented to the ATINER Visual Performing Arts Conference in 2013 entitled "Augmented Reality iPhone/iPad App Development to Visualise Roman Leicester (Ratae Corieltavorum) described the research, design and development of a GPS location based mobile app which showed $3 D$ reconstructions of buildings and objects in Roman Leicester (Ratae Corieltavorum) focusing on the period around 210 A.D. This development was part of the Virtual Romans project which began in 2008 whose aim was to explore the potential for using creative technologies to present life in Roman Leicester. In this follow on paper we describe the launch of the app and its subsequent evaluation with museum visitors in 2014. The results of the evaluation indicate that GPS inaccuracies can lead to low immersion, inconvenience and a reduced visitor experience. However the results also indicate that these digital technologies can be particularly engaging and exciting for children in terms of heritage interpretation. ${ }^{l}$

\section{Introduction}

The Romans settled in Leicester during the 1 st to $4^{\text {th }}$ Centuries A.D. ${ }^{2}$ The Virtual Romans project began in 2008 and its aim was to explore the potential of creative technologies to present our understanding of life in Roman Leicester formerly known as Ratae Corieltavorum. ${ }^{3}$ The project focused on the research and development of historically accurate digital $3 \mathrm{D}$ models of the known buildings and artifacts and with the eventual aim of populating the resulting town with virtual "Roman" characters. The building and artefact digital assets were made available to the public in January 2014 via a web site, ${ }^{4}$ an interactive kiosk and 3D printed building in Leicester's Jewry Wall Museum (which is on the site of the former Roman Baths) and an Apple iPad

\footnotetext{
* Programme Leader Digital Design, De Montfort University, U.K..

${ }^{\dagger}$ PG Student, University of Newcastle, U.K..

* Principle Lecturer, De Montfort University, U.K.

1.Virtual Romans Web site: http://bit.ly/1PqwHRD, Virtual Romans App: http:// pple. co/1RE14mT.

2. R Buckley et al., Visions of Ancient Leicester, (University of Leicester School of Archeology and Ancient History, 2011).

3. A. Hugill, Virtual Romans, (2012), http://bit.ly/1Mo7jGG.

4. N Higgett et al, Virtual Romans (2015), http://bit.ly/1PqwHRD.
} 
app. Earlier papers have already described the development of the app. ${ }^{5}$ This paper provides a brief overview of the app but focuses on its evaluation and explores the potential of its use of location based mobile and augmented reality technologies in a virtual heritage context. The app was a collaboration between De Montfort University, the Leicester City Arts and Museum Service's Jewry Wall Museum and the University of Leicester's Archaeological Service. The evaluation has been conducted by the University of Newcastle in collaboration with De Montfort University.

\section{Background}

\section{New Technologies}

With new development of Information and Communication Technologies (ICTs), there has been a decrease in the costs required to apply ICTs to museum and heritage management, education, interpretation or interaction. As a result ICTs have been widely introduced to museums and heritage sites. ${ }^{7}$ conclude that "information technologies provide solutions to issues of space limitation, exhibitions costs and curator's concerns about the fragility of some museum artefacts".

Augmented Reality (AR) and Virtual Reality (VR) technologies are recognised to have significant potential benefits for museums and heritage sites. AR and VR mainly contribute to the development and enhancement of virtual reconstructions, personal navigated tours and interactive visualisations of archaeological finds and heritage. These innovative methods and tools of emerging AR, VR and other ICT's can make the content and context of museum collections, archaeological findings and heritage research more accessible and attractive to wider range of visitors. Moreover, the user experience can be enhanced by new ways of presentation and interpretation. ${ }^{8}$

With the widespread use of new "smart" mobile communication devices, the problems of AR and VR customer devices identified previously, for example inaccurate navigation, weight, complicated operation, data calculation and related software design, are being solved. Newer devices offer the GPS compasses, cameras, data connectivity, high resolution screens, computation

5. N. Higgett et al, "Virtual Romans: Virtual Reconstruction of Roman Leicester (Ratae Corieltauvorum) 210 AD" (VAST: International Symposium on Virtual Reality, Archaeology and Intelligent Cultural Heritage-Short and Project Papers, The Eurographics Association, 2012).

6. N Higgett et al, "Augmented Reality iPhone/iPad App Development to Visualise Roman Leicester (Ratae Corieltavorum)" ( presentation, Annual International Conference on Visual and Performing Arts, Athens, Greece, June, 2013).

7. S. Styliani et al., "Virtual museums, a survey and some issues for consideration," Journal of Cultural Heritage 10, no. 4 (2009): 520-528.

8. Ibid. 
power and software required. ${ }^{9}$ As a result, the age of AR and VR adoption to visitor service in museum and heritage is coming.

\section{Augmented Reality (AR)}

Augmented reality is normally considered as an upgrade of virtual reality. As defined by Miheij, Novak and Begus (2013), augmented reality can augment an image of the real world (seen by user) with a computer-generated image that enhances the real image with additional information. ${ }^{10}$ The additional data facets are mainly constituted by textual, photographic and graphical information, 3D graphics or video. ${ }^{112}$ The additional layers of digital data add to the real world image augmenting the real world with virtual information. ${ }^{13} 14$

For museum and heritage sites, augmented reality can merge computer generated virtual reconstruction of museum collections and ruined or lost historical sites to the real environment. Furthermore, other types of additional data can also be overlaid such as textual or video interpretation.

As Miheij, Novak and Begus (2013) explained, augmented reality can "improve user perception and increase his/her effectiveness through additional information". ${ }^{15}$ User`s interest in museum collections, exhibitions and historical heritage sites can be effectively stimulated by using AR to engage users with the environment where they visit. Augmented reality enables an alternative way of museum interaction, navigation and interpretation compared to the traditional "brick and mortar" museum. This point is especially significant "when museums do not have the space and resources required to exhibit their whole collection or the nature of some of the objects prevent the museums making them available to the public". ${ }^{16}$ Furthermore, augmented reality also enables the visualisation of broken or incomplete objects by means of overlaying the missing parts to the original parts. Interaction with an AR system in real time provides an opportunity for users to have an intuitive

9. H. E. Pence, "Smartphones, Smart Objects, and Augmented Reality," The Reference Librarian 52, no. 1-2 (2010): 136-145.

10. M. Mihelj et al., Virtual Reality: Technology And Applications, (Dordrecht : Springer, 2013), http://bit.ly/1VPkxGW.

11. H. E. Pence, "Smartphones, smart objects, and augmented reality," The Reference Librarian 52, no 1-2 (2010): 136-145.

12. Michael Gallagher, Flaneur, Augmented Reality in Mobile Tech and Lower Manhatton, accesed July 22, 2014, http://bit.ly/1K5VX8I.

13. M. Mihelj et al., Virtual Reality: Technology And Applications, (Dordrecht : Springer, 2013), http://bit.ly/1VPkxGW.

14. H. E. Pence, "Smartphones, Smart Objects, and Augmented Reality," The Reference Librarian 52, no 1-2 (2010): 136-145.

15. M. Mihelj et al., Virtual Reality: Technology And Applications, (Dordrecht : Springer, 2013), http://bit.ly/1VPkxGW.

16. A. Angelopoulou et al., "Mobile Augmented Reality for Cultural Heritage," in Mobile Wireless Middleware, Operating Systems, and Applications, (London: Springer, 2012), 15-22. 
experience and gain understanding by merging content from both the real and virtual world.

It has been recognized by several researchers that handheld displays, especially smartphones and tablet computers, are the ideal platform for VR and AR application, which means that mobile augmented reality, has huge potential in the future. ${ }^{17} 1819$ The devices have the necessary components to run AR/VR systems, such as camera, accelerometers, digital compasses, global positioning systems and touch screen. They also present great opportunities for cultural institutions to reduce the cost of investment in AR/VR hardware infrastructure by taking advantage of the users' own devices. ${ }^{20}$ Smart phone or tablet based $\mathrm{AR} / \mathrm{VR}$ allows visitors to visualize, interact and navigate in the virtual simulation of museum and heritage sites.

\section{Current Adoption}

In the last few years, several museums and heritage sites, including Ancient Greek Olympia archaeological sites, British Museum and Natural History Museum, have involved and implemented VR and AR technologies in interpretation, education and management aspects. Representative cases of the adoption of virtual reality and augmented reality in museums and heritage sites include:

- ARCHEOGUIDE which is short for an EU founded project called Augmented Reality-based Cultural Heritage On-site Guide ${ }^{21} 22$

- The Allard Pierson Museum in Amsterdam has created an interactive virtual reality reconstruction of one of the top Etruscan tombs and archaeological objects fund in the tomb. ${ }^{23}$

- Intelligent Tourism and Cultural Information Through Ubiquitous Services (iTacitus) was designed for using augmented reality on the mobile computer to add the layer of virtual cultural heritage representations which is composed of three-dimension objects and background information to the physical reality. ${ }^{242526}$

17. Ibid

18. H. E. Pence, "Smartphones, smart objects, and augmented reality," The Reference Librarian 52, no 1-2 (2010): 136-145.

19. S. Styliani, et al., "Virtual museums, a survey and some issues for consideration," Journal of Cultural Heritage 10, no. 4 (2009): 520-528.

20. A. Angelopoulou et al., "Mobile Augmented Reality for Cultural Heritage," in Mobile Wireless Middleware, Operating Systems, and Applications, (London: Springer, 2012), 15-22.

21. V. Vlahakis et al., "Archeoguide: First Results of an Augmented Reality, Mobile Computing System In Cultural Heritage Sites," (Proceedings of the Conference on Virtual Reality, Archeology, and Cultural Heritage. NY: ACM, 2001), 131-140.

22. V. Vlahakis, et al., "Archeoguide: An Augmented Reality Guide for Archaeological Sites." IEEE Computer Graphics and Applications 22, no. 5(2002): 52-60.

23. "Museums in the digital age are alive and kicking' Heritage Sandbox," React, accessed July 22, 2014, http://bit.ly/1LrW7fN.

24. H. E. Pence, "Smartphones, Smart Objects, and Augmented Reality," The Reference Librarian 52, no 1-2 (2010): 136-145. 
- Yuanmingyuan Palace (Old Summer Palace) sites in Beijing of China is an application developed to use on iPad using the technique of mobile AR to digitally recreate some representative sites in Yuanmingyuan. ${ }^{27}$

The Virtual Romans application provides another example of the use of both AR and VR in a heritage /museum context.

\section{Overview of the Virtual Romans Application}

The initial aim of Leicester's Jewry Wall Museum was to adopt VR and AR to "bring the past of Roman time to life". The museum wanted to use modern technology to help people understand what the town and archaeological objects would have looked like when they were inhabited during the Roman period.

To enhance visitor experience and to improve interpretation were the two main objectives of the Jewry Wall Museum to develop and implement Virtual Romans. It was planned to enrich the visitor experience by improving interpretation and help people not only to understand what life was like in the Roman town but also to be able to relate it to the modern city in which they live or visit.

This was achieved by De Montfort University by creating an iPad application utilising GPS, without any markers, in combination with augmented reality technologies such that virtual 3D models could be visually superimposed on the view of the sites as seen in real-time through the mobile device camera. This accuracy of this overlay was enhanced by use of the device's accelerometer, gyroscope and magnetometer.

Figures 1-3 show the app in action.

25. Michael Gallagher, Flaneur, Augmented Reality in Mobile Tech and Lower Manhattan, accessed July 22, 2014, http://bit.ly/1K5VX8I.

26. M. Zoellner et al., "iTACITUS-Novel Interaction and Tracking Paradigms for Mobile AR," in The European Research Network of Excellence in Open Cultural Heritage (EPOCH): Vast2007 - Future Technologies to Empower Heritage Professionals : Short and Project Papers from VAST 2007., ed. David Arnold, 110-117. (Budapest : Archaeolingua, 2007).

27. Beijing Tsinghua Tongheng Planning and Design Institute, Yuanmingyuan, (2015), http://apple.co/1NDSHcb. 


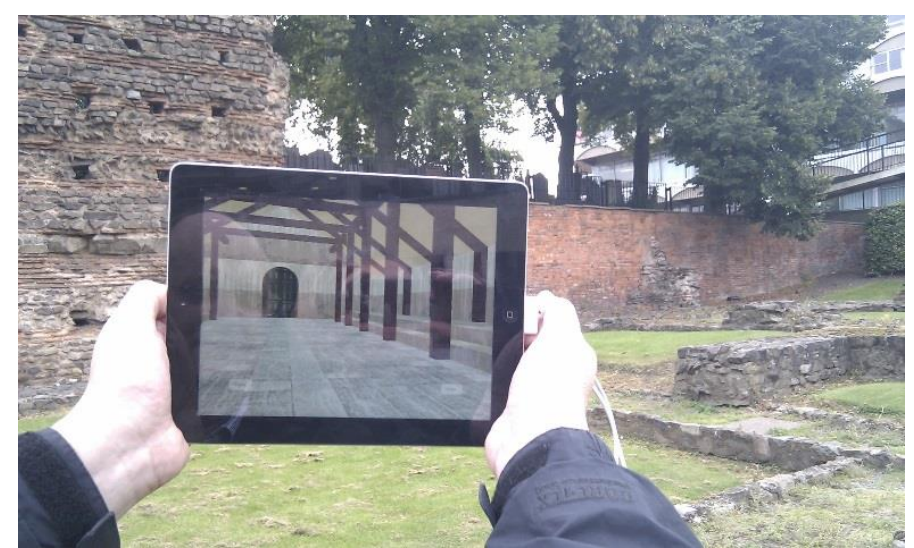

Figure 1. Interior of the Roman Jewry Wall Baths actually on the site of Roman Baths in Leicester

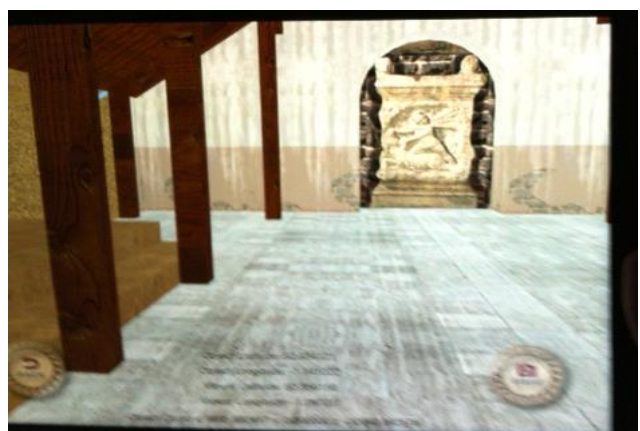

Figure 2. Photograph of Display Showing AR View inside the Mithraeum

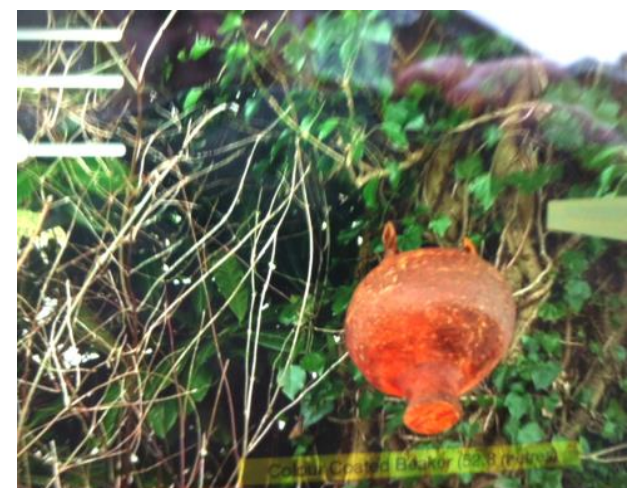

Figure 3. Photograph of Display Showing AR View of Colour-Coated Beaker Superimposed On Present Day Video Background of Find Location

The app provides both a map and gallery interface as a way of navigating the 3D AR content including Roman buildings and museum objects. See figures 4 and 5. 
Figure 4. Map Overlay
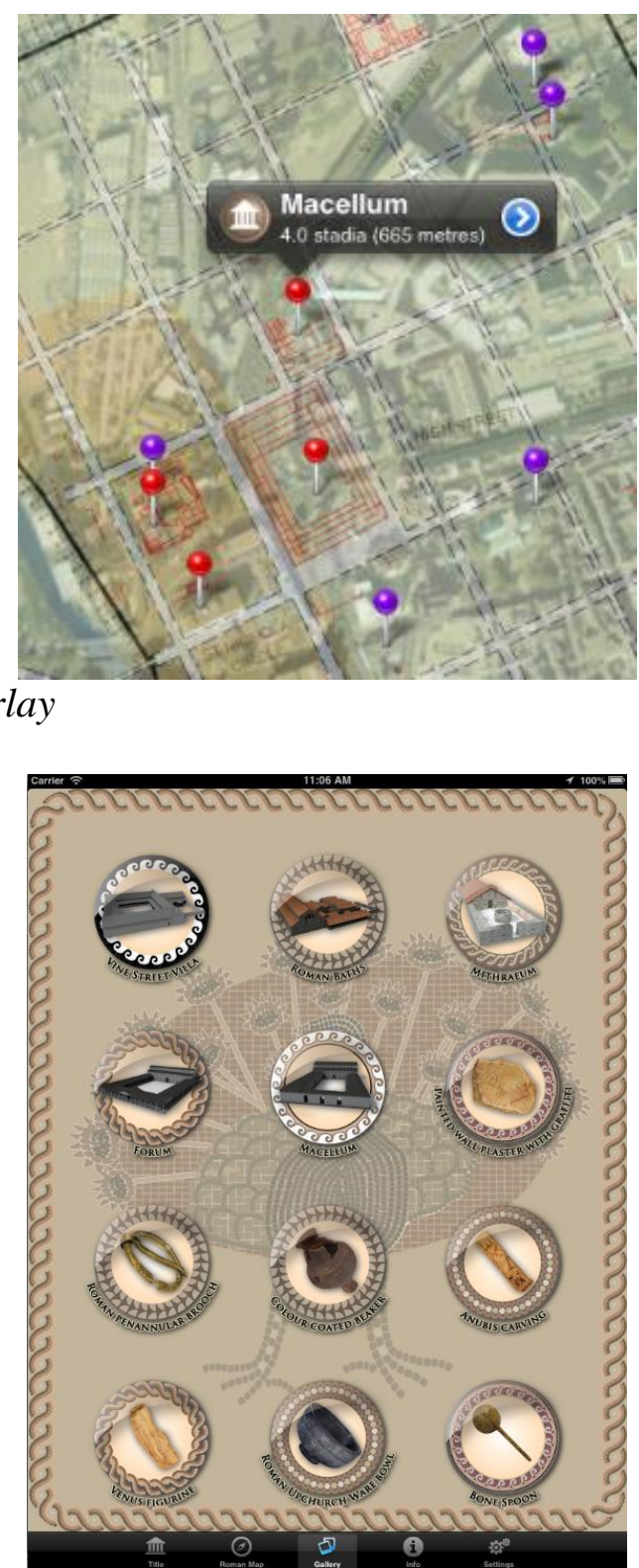

Figure 5. Gallery Page

\section{Application Evaluation}

Evaluation Methodology

Using mobile augmented reality technology, the Virtual Romans application allows users to add the image of the virtual reconstructed Roman Bath to the real-time image of the site taking from the camera. The evaluation research explored the specific visitor experience and how it is affected by the Virtual Roman Application's adoption of virtual reality and augmented reality technologies through a visitor survey at the Roman Bath site located outside the Jewry Wall Museum, which is one of the five virtually reconstructed sites. 
The research utilised a self-administered visitor questionnaire to explore the impact on visitor experience of using this AR/VR application. As suggested by researchers Bryman (2012), Corbetta (2003) and Creswell (2009), research data should be collected from a diversified sample so that bias is reduced and the generalisability of the results is enhanced. ${ }^{28} 29{ }^{30}$ This research employed a random and self-administered visitor questionnaire to avoid the bias of visitor survey results.

The data collection of visitor questionnaire was conducted from 5th to 10th August 2014 at Roman Bath site and Jewry Wall Museum. Three sessions were conducted first by inviting and introducing the functions of the application and then asking visitors to complete the self-administered questionnaire. Visitors were randomly invited to experience the Virtual Romans app on an iPad by walking around the remains of Roman Bath and interacting with the virtual reconstructed Roman Bath buildings which can be superimposed on the real image of bath foundation at Jewry Wall. After completing their visit, they were invited to answer the questionnaire which included ten qualitative questions about their experience or intention.

43 questionnaires were distributed to visitors and 40 questionnaires were completed and returned. These 40 interviewees consisted of 13 female and 25 male participants. There were 2 interviewees who were unwilling to leave their gender information.

\section{Data Analysis}

\section{Realistic, Intuitive and Informative Experience}

The data indicated that most visitors enjoyed their visit using the AR/VR reconstructed presentations in the Virtual Romans application. The majority claimed that they had an interesting, intuitive and informative experience. Viewing the AR/VR reconstructed Roman Bath and historical artifacts enhanced visitor understanding of the site and collections, making it easier to visualise. Over half of visitors (28 out of 40) experienced levels of immersion from the AR/VR environments, which mainly came from their interaction and enjoyment of seeing the reconstructed Roman buildings.

The results indicate that AR/VR system can aid visitors in freely exploring the site outside of the main museum building and was more exciting for some visitors compared to reading interpretation boards or looking at objects presented in display cases. The application also provided visitors with more choices of interpretation according to their interests and preference.

In addition, 34 visitors stated they were able to get a more comprehensive perspective through the integrated presentation of the virtual reconstructed heritage sites and objects. Visitors found that it was easier to understand the

28. A Bryman, Social Research Methods. (Oxford: Oxford University Press, 2012).

29. P Cobbeta, Social Research: Theory, Methods and Techniques (London: Thousand Oaks, Calif.: SAGE Publications, 2003).

30. J. W. Creswell, Research Design: Qualitative, Quantitative, and Mixed Methods Approaches (Thousand Oaks, Calif.: Sage Publications, 2009). 
relationship between different Roman sites and artifacts within the city by viewing them together. This seems to validate the aim of the Jewry Wall Museum to use modern technology to show what life was in the Roman town compared to the present city in order to enhance visitor's understanding. Because of the realistic and intuitive experience provided by the AR/VR environments, the majority (38 out of 40) of visitors said they would recommend their experience and the Virtual Romans application to others.

\section{Interaction}

According to the data, the high levels of interaction provided by the application enriched their experience. 19 visitors claimed that looking at 3D reconstructions was better than $2 \mathrm{D}$ images, because they could interact with an object by "turning" or even "picking it up" to explore more details according to their interests. The majority of visitors (34 out of 40) thought that to "walk in" the digital reconstructed Roman Bath and to "turn" the 3D objects allowing them to explore them in more detail were the most impressive experiences of their visit. After these interactions, 22 visitors also said they were stimulated to learn more about what they had experienced, and there were also some visitors willing to plan a visit to other Roman sites in order to expand their understanding of Roman Leicester.

\section{Interpretation}

14 visitors said they liked the traditional interpretation because they thought the textual explanations and physical displays provided instant information about the objects and their context. Moreover, 5 visitors did not enjoy the 3D reconstruction of archaeological objects and said they actually preferred the traditional interpretation. This group felt they needed to get extra information from a textual explanation after viewing the digital presentation.

However, a majority of visitors (29) preferred the AR/VR interactive interpretation claiming it allowed them to visualise the detail of the Roman Baths and related objects, which was impossible to achieve by means of traditional interpretation. Some visitors felt the reconstruction also gave them a more intuitive personal understanding unlike the traditional panels.

12 visitors mentioned that they liked to use a combination of both these interpretation forms as they can inform visitors in different ways and provide more choices depending on a visitor's needs. However 4 of these visitors preferred to read more detailed information from traditional textual explanations.

These results indicate that this type of AR/VR interpretation can enhance the visitor experience; however some visitors still prefer the traditional form of interpretation.

\section{Family Visitors with Children}

The data also indicated that using a tablet and the AR/VR application, significantly increased the interest of visiting children and young people. Most of them found it exciting and interesting to see and go inside the virtual 
reconstructed buildings and gain new knowledge from the 3D objects. 9 parents felt the application was intuitive and made it easier for them to explain the site and museum collections to these young people. The questionnaire data results indicate the majority of children had a good and interesting learning experience. The implication for school education is that a museum or heritage AR/VR application might stimulate student interest in history or related subjects.

\section{Visitors with Specific Interests}

According to the questionnaire results, visitors with a specific interest in history and archaeology felt the experience of VR and AR could enrich their visit, but at least one felt they could get the same information from the traditional textual information or other traditional interpretation forms. Several also thought the traditional interpretation contained more information than the AR/VR presentation.

\section{Tracking}

It was concluded from the questionnaire results, that the inaccuracy and instability of GPS tracking created considerable confusion for visitors. The fact that the Roman Baths did not always appear where they were supposed to be was the mostly criticized aspect of the Virtual Romans application by visitors. This was due to the limitations of the outdoor GPS positioning. Another related problem reported was that the GPS tracking did not change promptly with the movement of visitors. This problem with GPS tracking reduced the immersive feeling for visitors and consequently their satisfaction with the use of the application.

\section{Inconvenience of Hardware}

Some visitors thought the iPad's screen was not large enough to look at the VR /AR reconstruction. This is clearly an issue with mobile augmented reality. However, these devices are more portable for visitors to carry.

Some visitors also criticized the iPad stating that it was difficult to hold during their visit.

\section{Discussion}

Realistic, Intuitive and Informative Experience with Interaction

Visitors can generally get a realistic, intuitive and interactive experience from their participation with VR and AR environments. This aspect of experience has also been widely identified by other researchers. ${ }^{31}{ }^{32}$ This paper

31. V. Vlahakis et al., "Archeoguide: First Results of an Augmented Reality, Mobile Computing System In Cultural Heritage Sites," (Proceedings of the Conference on Virtual Reality, Archeology, and Cultural Heritage. NY: ACM, 2001), 131-140. 
argues that visiting an heritage site with the aid of an AR/VR reconstruction can help visitors enhance their understanding of the site and increase their enjoyment.

It is also argued that an AR/VR application gives visitors more freedom to personalize their visit. This finding is consistent with the research by Vlahakis, Karigiannis et al. (2001) and Bruno et al. ${ }^{33}{ }^{34}$ The application allows visitors to plan their visit depending on their own interests.

The results indicate that visitors can get a comprehensive perspective and understanding from the integrated presentation of different heritage aspects using augmented reality and virtual reality technologies. AR/VR reconstructions of heritage can provide visualizations allowing visitors to easily understand heritage in a broader spatial and temporal context. This point supports the visitor research result found by Bruno et al. ${ }^{35}$ in MNEME project, which enables visitors to overcome the limitation of space and time in understanding the context of a heritage site as a whole. Furthermore, an AR /VR representation can put historical heritage into the context of the modern landscape, in order to help visitors link history with their own present day life. This concept is also mentioned by Kang and Buhalis, Owen et al. ${ }^{36}{ }^{37}$ AR/VR technology allows visitors to compare their current environment with the past which can enhance both visitor experience and understanding.

\section{Interpretation}

Some visitors said they preferred the AR/VR interactive interpretation to traditional interpretation because they felt the traditional textual explanation was based on a researcher's interpretation while AR/VR gave them the freedom to explore and make their own interpretation. However, this view does not entirely recognise the fact that the AR/VR presentation is also based on the research by archaeologists, scientists and other related researchers. Styliani, Fotis et al. (2009) claim that when scientists reconstruct some item with

32. M Puyuelo et al., "Experiencing Augmented Reality as an Accessibility Resource in the UNESCO Heritage Site Called "La Lonja," Valencia' Journal of Procedia Computer Science, 25 (2013): 171-178.

33. V. Vlahakis et al., "Archeoguide: First Results of an Augmented Reality, Mobile Computing System In Cultural Heritage Sites," (Proceedings of the Conference on Virtual Reality, Archeology, and Cultural Heritage. NY: ACM, 2001), 131-140.

34. F. Bruno et al., "From 3D Reconstruction to Virtual Reality: A complete Methodology for Digital Archaeological Exhibition," Journal of Cultural Heritage 11, no. 1 (2010): 42-49.

35. F Bruno et al., "From 3D Reconstruction to Virtual Reality: A complete Methodology for Digital Archaeological Exhibition," Journal of Cultural Heritage 11, no. 1 (2010): 42-49.

36. J. Kang, "AR Teleport: Digital Reconstruction of Historical and Cultural-Heritage Sites Using Mobile Augmented Reality," in Trust, Security and Privacy in Computing and Communications (TrustCom), IEEE 11th International Conference on, IEEE, 25-27 June 2012, $1666-1675$.

37. D Buhalis et al., "Information Communication Technology Applications for World Heritage Site Management," in Managing World Heritage Sites, ed. Anna Leask and Alan Fyall (Elsevier, 2006), 125-144. 
missing elements, they rely on related research or their own judgment to recreate it. ${ }^{38}$ This personal or subjective element is present in any interpretation whether virtual or not rather than being a true representation of the past.

\section{Wider Users}

Visitors with different needs can benefit from the flexible contents of AR/VR representations. People with specific interests or needs can get access to information according to what they require. This result is consistent with research concerning virtual museums carried out by Styliani, Fotis et al. (2009). ${ }^{39}$ They believe that virtually reconstructed heritage environments enable a wider range of end-user groups to access to museum collections and heritage content.

For example, children particularly enjoyed the interaction with the AR/VR environment. The majority of children found the application an interesting and exciting experience. It is argued therefore that the use of AR/VR technologies in museum and heritage sites can enhance children's and young people's interest and learning. This result has also been recognized and by the British Museum, who have developed the Digital Discovery Centre using virtual reality and augmented reality to enhance the interest and interaction of children and young people with museum collections. ${ }^{40}$ The technology has been similarly adopted by the Natural History Museum to help visitors intuitively understand the life of the earth in the past time. ${ }^{41}$

In order to meet these needs of a wide range of users effectively, developers need to conduct a visitor segmentation survey first to understand the specific needs or interests of museum and heritage's main visitor groups before designing and implementing an AR/VR application. Virtual Romans failed in this process and even though it seems to be successful an even better solution could have been developed if visitor needs had been formally assessed.

\section{Improvement to Software and Hardware}

Visitors get confused when the tracking result is not stable or accurate. As pointed out by Seo, Kim et al. (2010), "Tracking is a core technology for ARbased tour guides because it enables the correct presentation of virtual content to tourists according to their different locations and viewpoints", ${ }^{42}$ so providing fully-immersive experience is highly reliant on the accuracy of tracking results. The results of this study support this view. The unstable and inaccurate GPS

38. Styliani, S., et al., "Virtual museums, a survey and some issues for consideration," Journal of Cultural Heritage 10, no. 4 (2009): 520-528.

39. Ibid.

40. "Samsung and the British Museum announce five-year partnership renewal," British Museum, accessed July 28, 2014, http://bit.ly/1JONiwy.

41. "Interactive film - Who do you think you really are?," Natural History Museum, http://bit.ly/1Zydemh.

42. B. K. Seo et al., "A tracking framework for augmented reality tours on cultural heritage sites," Proceedings of the 9th ACM SIGGRAPH Conference on Virtual-Reality Continuum and its Applications in Industry (ACM, 2010). 
tracking in the Virtual Romans app was the most criticized feature by visitors; this is because the accuracy of GPS tracking is limited to several meters. In this type of small scale heritage site, even a small deviation in location can impact negatively on the AR presentation. Location tracking is therefore an important aspect which should be improved in the future perhaps using some marker based system or micro-location technology such as iBeacons.

Hardware issues, specifically the screen size of the mobile devices, also reduced the fun aspect of the visitor experience. Some visitors thought the iPad screen was too small to view detailed VR and AR reconstructed buildings. This result supports the research by Pence (2010), who argued that mobile devices are not big enough to display VR and AR even though they have the advantage of being portable. ${ }^{43}$ In addition, some visitors felt that holding the mobile devices was inconvenient. Similar concerns have also been reported by Vlahakis, Karigiannis et al. (2001), Vlahakis, Ioannidis et al. (2002) and Kang (2012). ${ }^{44} 4546$

There is therefore a conflict between the high portability and image quality required by visitors and the hardware limitations of current technology. It is hoped this issue will be addressed in future by developments in wearable AR/VR technologies such as the Epson Moveiro BT-200

\section{Conclusions}

The survey $(n=40)$ indicated the visitors, on the whole, enjoyed the Virtual Romans AR/VR application and felt it was intuitive, informative and realistic.. They felt it enhanced the visitor's understanding of the site and collections and made it easier to visualise. The original aim of the museum to use virtual reality and augmented reality to provide innovative ways to engage local audiences has therefore been achieved. Some of the family visitors thought that Virtual Romans made it easier to explain information about the site and museum collections.

This novel 3D delivery system would appear to have particular appeal to younger visitors who found it both interesting and exciting. Parents and grandparents expressed the view that Virtual Romans enhanced their children`s learning and interest in the Roman Baths they visited as well as in local history.

43. H. E. Pence "Smartphones, smart objects, and augmented reality." The Reference Librarian 52, no. 1-2 (2010): 136-145.

44. V. Vlahakis et al., "Archeoguide: First Results of an Augmented Reality, Mobile Computing System In Cultural Heritage Sites," (Proceedings of the Conference on Virtual Reality, Archeology, and Cultural Heritage. NY: ACM, 2001), 131-140

45. V. Vlahakis, et al., "Archeoguide: An Augmented Reality Guide for Archaeological Sites." IEEE Computer Graphics and Applications 22, no. 5(2002): 52-60.

46. J. Kang, "AR Teleport: Digital Reconstruction of Historical and Cultural-Heritage Sites Using Mobile Augmented Reality," in Trust, Security and Privacy in Computing and Communications (TrustCom), IEEE 11th International Conference on, IEEE, 25-27 June 2012, $1666-1675$. 
A boy of about 7 years of age mentioned that he would like to let his teacher know about the Virtual Romans app and his classmates as well.

The main problem identified by most visitors was the inaccurate GPS tracking. This negatively affected user experience and reduced the level of immersion. In addition some visitors also criticised the small screen size. Both these issues will be considered in any future work. This was primarily a technology led design project. However, time permitting any future work in this area would also benefit from study at the beginning of the project to determine user needs as well as having more user involvement during the development process.

\section{Acknowledgments}

Our special thanks to Andrew Newman Senior Lecturer in Museum Studies at the University of Newcastle who was Yanan's supervisor during this evaluation research. Many thanks also to Laura Hadland at the Jewry Wall Museum in Leicester and Richard Buckley at the University of Leicester who provided all the historical advice. Additional thanks to Gerardo Saucedo, Dave Everitt, Russell White, Lee Dennis, Emily Baines, Ryan Chen and Stella Zhao at De Montfort University who all contributed to the app's development.

\section{Bibliography}

Angelopoulou, A., et al. (2012). "Mobile Augmented Reality for Cultural Heritage". In Mobile Wireless Middleware, Operating Systems, and Applications. London: Springer, 15-22.

Beijing Tsinghua Tongheng Planning and Design Institute, Yuanmingyuan, 2015. http://apple.co/1NDSHcb.

"Samsung and the British Museum announce five-year partnership renewal." British Museum. Accessed July 28, 2014. http://bit.ly/1JONiwy.

Bruno, F., et al. "From 3D reconstruction to virtual reality: A complete methodology for digital archaeological exhibition." Journal of Cultural Heritage 11, no. 1 (2010): 42-49.

Bryman, A. Social Research Methods. Oxford: Oxford University Press, 2012.

D Buhalis et al. "Information Communication Technology Applications for World Heritage Site Management." In Managing World Heritage Sites, edited by Anna Leask and Alan Fyall, 125-144. Elsevier, 2006.

Buckley, R. et al. Visions of Ancient Leicester. University of Leicester School of Archeology and Ancient History, 2011.

Cobbeta, P. Social Research: Theory, Methods and Techniques. London: Thousand Oaks, Calif.: SAGE Publications, 2003.

Creswell, J. W. Research Design: Qualitative, Quantitative, and Mixed Methods Approaches. Thousand Oaks, Calif.: Sage Publications, 2009.

Gallagher, M. Flaneur, Augmented Reality in Mobile Tech and Lower Manhattan. Accessed July 22, 2014. http://bit.ly/1K5VX8I. 
Higgett, N., et al. Virtual Romans: Virtual Reconstruction of Roman Leicester (Ratae Corieltauvorum) 210 AD. VAST: International Symposium on Virtual Reality, Archaeology and Intelligent Cultural Heritage-Short and Project Papers, The Eurographics Association, 2012.

Higgett, N., et al. "Augmented Reality iPhone/iPad App Development to Visualise Roman Leicester (Ratae Corieltavorum)." Presentation at the Annual International Conference on Visual and Performing Arts, Athens, Greece, June 2013.

Hugill, A. Virtual Romans. Accessed November 1, 2012. http://bit.ly/1Mo7jGG.

Kang, J. "AR Teleport: Digital Reconstruction of Historical and Cultural-Heritage Sites Using Mobile Augmented Reality." In Trust, Security and Privacy in Computing and Communications (TrustCom), IEEE 11th International Conference on, IEEE, 25-27 June 2012, 1666 - 1675.

"Interactive film - Who do you think you really are?," Natural History Museum, http://bit.ly/1Zydemh.

Mihelj, M., Novak, D. and Begus, S. Virtual Reality: Technology And Applications. Dordrecht: Springer 2013. http://bit.ly/1VPkxGW.

"Museums in the Digital Age Are Alive and Kicking Heritage Sandbox." React. Accessed July 22, 2014. http://bit.ly/1LrW7fN.

Pence, H. E. "Smartphones, Smart Objects, and Augmented Reality." The Reference Librarian 52, no. 1-2 (2010): 136-145.

Puyuelo, M. et al. "Experiencing Augmented Reality as an Accessibility Resource in the UNESCO Heritage Site Called "La Lonja." Valencia' Journal of Procedia Computer Sience 25, (2013): 171-178.

Seo, B.-K., et al. A Tracking Framework For Augmented Reality Tours On Cultural Heritage Sites. Proceedings of the 9th ACM SIGGRAPH Conference on VirtualReality Continuum and its Applications in Industry, ACM: 2010.

Styliani, S., et al. "Virtual museums, a survey and some issues for consideration." Journal of Cultural Heritage 10, no. 4 (2009): 520-528.

Tatham (n.d.) Virtual Romans App - Virtual and Augmented Reality Reconstruction of Roman Leicester [online] available from < http://www.heritagenetwork.dmu. ac.uk/virtual-romansapp-virtual-and-augmented-reality-reconstruction-of-romanleicester/> [3 August 2014 ]

Vlahakis, V. et al. "Archeoguide: First Results of an Augmented Reality, Mobile Computing System In Cultural Heritage Sites." Proceedings of the Conference on Virtual Reality, Archeology, and Cultural Heritage. NY: ACM, 2001, 131-140.

Vlahakis, V., et al. "Archeoguide: an augmented reality guide for archaeological sites." IEEE Computer Graphics and Applications 22, no. 5 (2002): 52-60.

Zoellner, M., et al. "iTACITUS-Novel Interaction and Tracking Paradigms for Mobile AR." In The European Research Network of Excellence in Open Cultural Heritage (EPOCH): Vast2007 - Future Technologies to Empower Heritage Professionals: Short and Project Papers from VAST 2007, edited by David Arnold, 110-117. Budapest: Archaeolingua, 2007. 
